\title{
Markers of Endothelial Damage, Inflammation, Oxidative and Cellular Stress in Patients with Coronary Artery Disease and Type 2 Diabetes
}

\author{
Julia A. Kotova, PhD*; Anna A. Zuikova, PhD, ScD; Aleksander N. Pashkov, PhD, ScD; \\ Natalia V. Strahova, PhD; Olga N. Krasnorutskaya, PhD, ScD; \\ Veronika I. Shevzova, PhD; Elena Yu. Esina, PhD, ScD \\ Voronezh State Medical University named after N.N. Burdenko \\ Voronezh, the Russian Federation
}

\begin{abstract}
Results of this study present the features of the severity of coronary atherosclerosis, evaluated by the Gensini score, depending on the presence of T2D (type 2 diabetes). The presence of T2D aggravates the course of coronary heart disease due to the more pronounced processes of inflammation, endothelial dysfunction, and oxidative and cellular stress. (International Journal of Biomedicine. 2020;10(2):104-107.)
\end{abstract}

Key Words: coronary heart disease $\bullet$ type 2 diabetes $\bullet$ oxidative stress $\bullet$ endothelial dysfunction $\bullet$ inflammation

\section{Abbreviations}

ADPH, aldehyde derivative of DNPH; BMI, body mass index; CVDs, cardiovascular diseases; CHD, coronary heart disease; CAG, coronary angiography; DNPH, 2.4-dinitrophenylhydrazine; ED, endothelial dysfunction; FPG, fasting plasma glucose; GS, Gensini score; hsCRP, high-sensitivity C-reactive protein; HDL-C, high-density lipoprotein cholesterol; Hsp70, heat shock protein 70; KDPH, ketone derivative of DNPH; OS, oxidative stress; OMP, oxidative modification of proteins; SOD, superoxide dismutase; T2D, type 2 diabetes; tHcy, total homocysteine; WC, waist circumference.

\section{Introduction}

Usually caused by atherosclerosis, CHD constitutes a high level of mortality among CVDs-a leading cause of morbidity and mortality globally. ${ }^{(1-4)}$ Atherosclerotic plaque formation is a complex process that involves several mechanisms, including lipid accumulation, ED, OS, vascular proliferation, matrix degradation, chronic inflammation, and thrombosis. ${ }^{(5-7)}$ Oxidation of low-density lipoprotein cholesterol is one of the key factors for the development of atherosclerosis. Many factors are involved in the progression of atherosclerosis in patients with $\mathrm{T} 2 \mathrm{D}$; however, the most important factors are insulin resistance and hyperglycemia. ${ }^{(8-10)} \mathrm{T} 2 \mathrm{D}$ is characterized by accelerated atherosclerosis with widely distributed vascular

*Corresponding author: Julia Kotova, PhD. Voronezh State Medical University named after N.N. Burdenko. Voronezh, Russia. E-mail: kotova_u@inbox.ru lesions. People with diabetes are more likely to have carotid plaque with calcification and lipid-rich necrotic cores than people without diabetes. ${ }^{(11)}$ People with diabetes have a high incidence of two or more vessel diseases, compared with subjects without diabetes. ${ }^{(12)}$

Hyperglycemia is an important factor in cardiovascular damage, working through different mechanisms, such as activation of protein kinase $\mathrm{C}$, polyol and hexosamine pathways, and production of advanced glycation end-products. All of these pathways, in association with hyperglycemia-induced mitochondrial dysfunction and endoplasmic reticulum stress, promote accumulation of reactive oxygen species and activation of OS. ${ }^{(13,14)}$ The impact of chronic hyperglycaemia might induce damage on vascular homeostasis, mainly attributable to the endothelium function. Numerous observational studies have found increased levels of the mediators of inflammation, such as C-reactive protein (CRP), interleukin-6 (IL-6), plasminogen activator inhibitor 1 (PAI-1) Many studies have demonstrated an 
association between insulin resistance and accelerated CVD in patients with T2D. ${ }^{(15-18)}$ The strong association between insulin resistance and adverse cardiovascular outcomes in non-diabetic individuals and individuals with T2DM has been summarized in several meta-analyses. ${ }^{(19-21)}$

The aim of the present study was to evaluate the changes in the markers of endothelial damage and oxidative and cellular stress in CHD patients with T2D.

\section{Materials and Methods}

We examined 336 patients $(178 / 53 \%$ women and $158 / 47 \%$ men aged between 47 and 75 years, mean age of $61.8 \pm 8.1$ years) with CHD verified by standardized validated criteria and clinical-functional methods. T2D was detected in 70 out of 300 CHD patients.

All patients underwent the following examinations: assessment of traditional risk factors, physical examination, clinical and biochemical laboratory methods, 12-lead ECG, echocardiography, Holter ECG monitoring, treadmill test, and coronary angiography. Blood samples were obtained in the morning after a $12 \mathrm{~h}$ overnight fast. The levels of total cholesterol (TC), low-density lipoprotein cholesterol (LDL-C), high-density lipoprotein cholesterol (HDL-C), triglycerides (TG), and FPG were determined in the blood plasma. All patients underwent OGTT.

CAG was performed using General Electric Innova 3100 (GE Healthcare, USA). The transfemoral approach (the Seldinger technique) was used.

The severity of coronary atherosclerosis was evaluated by the GS. ${ }^{(22)}$ The severity of the disease is expressed as the sum of the scores for individual lesions and the functional importance index of the area of each lesion in the coronary tree. The sample was continuous.. According to the calculated GS, patients were divided into three groups: GS0 - 162 patients with normal coronary arteries, GS1 (115 points) -80 patients with hemodynamically insignificant coronary atherosclerosis, and GS2 (>15 points) - 94 patients with hemodynamically significant coronary atherosclerosis. As markers of OS, oxidized modified proteins and the SOD activity were determined. The determination of OMP in the blood serum was carried out using the methods by Dubinina et al. ${ }^{(23)}$ The assay is based on the spectrophotometric detection of the reaction between 2.4-dinitrophenylhydrazine (DNPH) with protein carbonyl to form protein hydrazone. The optical density of 2,4-dinitrophenylhydrazones derivates was recorded on an SF-36 spectrophotometer. The optical density of aldehyde- and ketone derivatives of a neutral character was recorded at $356 \mathrm{~nm}$ and $370 \mathrm{~nm}$, respectively (ADPHn and KDPHn). The optical density of aldehyde- and ketone derivatives of a basic character was recorded at $430 \mathrm{~nm}$ and $530 \mathrm{~nm}$, respectively (ADPHb and KDPHb).

The SOD activity was determined by the spectrophotometric method. The serum level of tHcy was determined by EIA using «Axis-Shield» test kit.

Hsp70 and their chaperone activity were considered as markers of cell stress. Extracellular Hsp70 was measured by ELISA (Elisa Kit for Hsp70, Cloud-Clone Corp.) in blood samples. Hsp70 chaperone activity was measured by monitoring the DTT-induced aggregation of insulin using recombinant Hsp70 (HSPA1A) (Cloud-Clone corp.). ${ }^{(24)}$

The level of high-sensitivity C-reactive protein (hsCRP) was determined using the High Sensitive Elisa Kit for CRP (Cloud-Clone Corp., USA).

Statistical analysis was performed using statistical software package SPSS version 20.0 (SPSS Inc, Chicago, IL). Median values are presented with interquartile (IQ) ranges (IQR; 25th to 75th percentiles). The Mann-Whitney test was used to compare median values. The frequencies of categorical variables were compared using Pearson $\chi^{2}$. The Spearman correlation coefficient $\left(r_{s}\right)$ was used to assess the relationship between variables. A probability value of $P<0.05$ was considered statistically significant.

\section{Results}

All patients were further divided into two groups, depending on the presence of T2D. Group 1 included $70 \mathrm{CHD}$ patients $(45.7 \%$ women and $54.3 \%$ men) with T2D; Group 2 included 266 CHD patients (54.9\% women and $45.1 \%$ men) without T2D. The characteristics of the compared groups are presented in Table 1. GS was significantly higher in Group $1(P=0.005)$ (Table 1). In Group 2, GS0 was determined in $51.8 \%$ of patients, GS1 in $25.6 \%$, and GS2 in $22.6 \%$. In Group 1, we saw the opposite trend: GS0 was determined in 23.3 of patients, GS1 in $17.1 \%$, and GS2 in $48.6 \%$.

Table 1.

The characteristics of the compared groups

\begin{tabular}{|l|c|c|c|}
\hline \multicolumn{1}{|c|}{ Variable } & Group 1 & Group 2 & $P$-value \\
\hline Age, $\mathrm{yrs}$ & $60.1 \pm 6.9$ & $58.8 \pm 5.8$ & 0.236 \\
\hline BMI, $\mathrm{kg} / \mathrm{m}^{2}$ & $27.6[25.7 ; 31.4]$ & $26.7[25.7 ; 27.9]$ & 0.118 \\
\hline $\mathrm{WC}, \mathrm{cm}$ & $92[82 ; 110]$ & $90[80 ; 98]$ & 0.071 \\
\hline $\mathrm{SBP}, \mathrm{mmHg}$ & $160[140 ; 180]$ & $140[140 ; 160]$ & 0.116 \\
\hline $\mathrm{DBP}, \mathrm{mmHg}$ & $90[90 ; 100]$ & $90[80 ; 98]$ & 0.005 \\
\hline GS, score & $11[0 ; 29]$ & $0[0 ; 12]$ & 0.005 \\
\hline
\end{tabular}

According to the parameters of the lipid spectrum, no significant differences between the two groups were found, with the exception of HDL-C, the level of which was lower in Group $1(P=0.032)$. The glucose level in Group 1 was 1.5 times higher than in Group 2. The levels of tHcy and hsCRP were significantly higher in Group 1 than in Group 2. At the same time, the SOD activity was lower in Group I than in Group $2(P=0.002)$. Markers of cell stress showed a tendency to increase in Group 1, compared with Group 2, indicating a more pronounced mitochondrial dysfunction and endoplasmic reticulum dysfunction in CHD patients with diabetes (Table 2). When evaluating OMP, a significant difference was established between these two groups in the blood levels of ADPHn $(P=0.009)$, KDPHn $(P=0.004)$, and $\mathrm{KDPHb}(P=0.045)$ (Fig. 1$)$. As is known, an increase in ADPHn indicates the activation of free radical processes, and an increase in KDPHn/b indicates a depletion of the adaptive performance. 
Table 2 .

Markers of endothelial damage, inflammation, oxidative and cellular stress in the compared groups

\begin{tabular}{|l|c|c|c|}
\hline \multicolumn{1}{|c|}{ Variable } & Group 1 & Group 2 & $P$-value \\
\hline TC, mmol/L & $5.9[4.5 ; 6.9]$ & $5.5[4.55 ; 6.2]$ & 0.311 \\
\hline LDL-C, mmol/L & $2.7[2.3 ; 3.7]$ & $2.6[2.1 ; 3.1]$ & 0.384 \\
\hline HDL-C, mmol/L & $1[0.9 ; 1.1]$ & $1.1[0.9 ; 1.1]$ & 0.032 \\
\hline TG, mmol/L & $1.3[1 ; 1.4]$ & $1.2[1.1 ; 1.5]$ & 0.757 \\
\hline FPG, $\mathrm{mmol} / \mathrm{L}$ & $7.9[6.4 ; 9.8]$ & $5.4[4.9 ; 5.8]$ & $5.96 \mathrm{E}-13$ \\
\hline tHcy, $\mu \mathrm{mol} / \mathrm{L}$ & $10.9[9.8 ; 12]$ & $10[9.5 ; 11.34]$ & 0.020 \\
\hline hsCRP, mg/L & $0.15[0.01 ; 0.76]$ & $0.02[0.005 ; 0.21]$ & 0.022 \\
\hline SOD, \% & $35.21[32.1 ; 37.6]$ & $38.3[35.21 ; 39.26]$ & 0.002 \\
\hline Hsp70, ng/ml & $1.43[1.02 ; 1.9]$ & $2.12[1.52 ; 2.88]$ & 0.0002 \\
\hline $\begin{array}{l}\text { Hsp70 chaperone } \\
\text { activity, \% }\end{array}$ & $65.9[52.7 ; 68.5]$ & $71.2[61.5 ; 76.1]$ & 0.001 \\
\hline
\end{tabular}

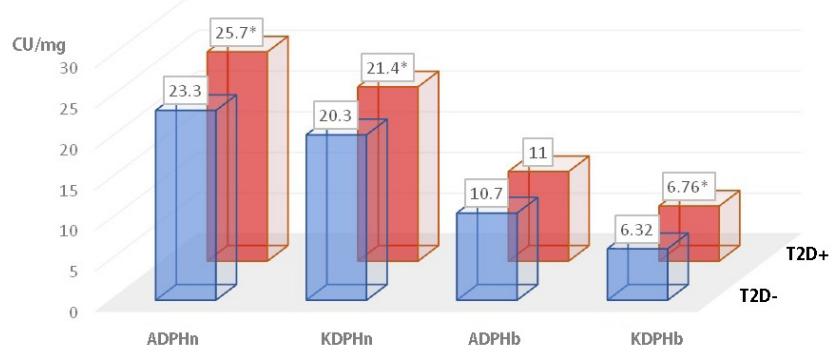

Fig.1. Parameters of OMP in the compared groups.

The lower chaperone activity was found in Group 1. As is known, chaperones play a huge protective role during cellular stress and pathologic conditions. Important redox modifications of chaperone proteins have been described in OS conditions. The activation of Hsp70 may play a role in protecting the cells against OS and inflammatory damage. ${ }^{(25)}$ HSP70 is susceptible to S-glutathionylation under oxidative stress conditions. It has been suggested that S-glutathionylation of HSP70 may potentiate its chaperone activity. ${ }^{(26)}$ In the setting of inducibly elevated Hsp70, cardiomyocyte protection was identified. ${ }^{(27)}$ Additionally, other studies have found a lower incidence of post-operative atrial fibrillation in patients with high levels of HSP70 (also known as HSP70-1a, HSP70-1b), in contrast to those with low HSP70 (or a HSP70 polymorphism with decreased function) who have an increased risk of post-operative atrial fibrillation. ${ }^{(28,29)} \mathrm{Hsp} 70$ participates in cardioprotection induced by exercise preconditioning, early and late protection, where Hsp70 repairs unfolded proteins or may stabilize the function of the endoplasmic reticulum. ${ }^{(30)}$

Correlation analysis revealed the relationships between the presence of T2D and GS $\left(\mathrm{r}_{\mathrm{s}}=0,217, P=0,005\right)$, the blood levels of ADPHn $\left(\mathrm{r}_{\mathrm{s}}=0.201, P=0.009\right)$, KDPHn $\left(\mathrm{r}_{\mathrm{s}}=0.221\right.$, $P=0.004), \mathrm{KDPHb}\left(\mathrm{r}_{\mathrm{s}}=0.155, P=0.044\right)$, SOD activity $\left(\mathrm{r}_{\mathrm{s}}=-0.237\right.$, $\mathrm{P}=0.002)$, Hsp70 $\left(\mathrm{r}_{\mathrm{s}}=-0.284, P=0.000\right)$, and chaperone activity $\left(\mathrm{r}_{\mathrm{s}}=-0.249, P=0.0001\right)$.
Thus, our study showed that the course of coronary atherosclerosis in CHD patients with T2D is more severe than in patients without T2D. The presence of T2D aggravates the course of CHD due to the more pronounced processes of inflammation, endothelial dysfunction, and oxidative and cellular stress.

\section{Competing Interests}

The authors declare that they have no competing interests.

\section{References}

1. Roth GA, Johnson C, Abajobir A, Abd-Allah F, Abera SF, Abyu G, et al. Global, Regional, and National Burden of Cardiovascular Diseases for 10 Causes, 1990 to 2015. J Am Coll Cardiol. 2017 Jul 4;70(1):1-25. doi: 10.1016/j. jacc.2017.04.052. Epub 2017 May 17.

2. Gaziano TA, Bitton A, Anand S, Abrahams-Gessel S, Murphy A. Growing epidemic of coronary heart disease in low- and middle-income countries. Curr Probl Cardiol. 2010 Feb;35(2):72-115. doi: 10.1016/j.cpcardiol.2009.10.002.

3. Ugurchieva PO, Didigova RT, Ugurchieva ZO, Mamedov $\mathrm{MN}$. [Five-year prognosis in patients with coronary heart disease and comorbidities: data from multicenter study in Ingushetia Republic]. Russian Journal of Cardiology.2018;(3):17-22. [Article in Russian].

4. Shalnova SA, Deev AD, Kapustina AV, Evstifeeva SE, Muromtseva GA, Tuaeva EM, et al. [Coronary heart disease in persons older than 55 years. Prevalence and prognosis]. Cardiovascular Therapy and Prevention. 2014;13(4):21-28. [Article in Russian].

5. Marchio P, Guerra-Ojeda S, Vila JM, Aldasoro M, Victor VM, Mauricio MD.Targeting Early Atherosclerosis: A Focus on Oxidative Stress and Inflammation.Oxid Med Cell Longev. 2019 Jul 1;2019:8563845. doi: 10.1155/2019/8563845. eCollection 2019.

6. Arabidze GG. [Clinical immunology of atherosclerosis from the theory to practice]. The Journal of Atherosclerosis and Dyslipidemias. 2013;(1):4-19.[Article in Russian].

7. Kotova YuA, Zuykova AA, Pashkov AN, Strahova NV, Krasnorutskaya ON. Markers of oxidative stress in patients with coronary heart disease. International Journal of Biomedicine. 2018;8(2):115-117.

8. Kim JA, Montagnani M, Koh KK, Quon MJ. Reciprocal relationships between insulin resistance and endothelial dysfunction: molecular and pathophysiological mechanisms. Circulation. 2006;113(15):1888-904.

9. Cubbon RM, Rajwani A, Wheatcroft SB. The impact of insulin resistance on endothelial function, progenitor cells and repair. Diab Vasc Dis Res. 2007;4(2): 103-11.

10. Liang CP, Han S, Senokuchi T, Tall AR. The macrophage at the crossroads of insulin resistance and atherosclerosis. Circ Res. 2007;100(11):1546-55.

11. Gao X, Song J, Watase H, Hippe DS, Zhao X, Canton $\mathrm{G}$, et al.; CARE-II Investigators. Differences in Carotid Plaques Between Symptomatic Patients With and Without Diabetes Mellitus. Arterioscler Thromb Vasc Biol. 2019 Jun;39(6):1234-1239. doi: 10.1161/ATVBAHA.118.312092. 12. Natali A, Vichi S, Landi P, Severi S, L'Abbate A, Ferrannini E. Coronary atherosclerosis in Type II diabetes: angiographic findings and clinical outcome. Diabetologia. 
2000 May;43(5):632-41.

13. Fiorentino TV, Prioletta A, Zuo P, Folli F. Hyperglycemiainduced oxidative stress and its role in diabetes mellitus related cardiovascular diseases. Curr Pharm Des. 2013;19(32):5695-703. 14. Vorozhtsova IN, Budnikova OV, Afanasyev SA, Kondratieva DS. [Influence of type 2 diabetes on the myocardium of patients with ischemic heart disease]. The Siberian Medical Journal. 2018;33(1):14-20. [Article in Russian].

15. Reaven GM, Knowles JW, Leonard D, Barlow CE, Willis BL, Haskell WL, Maron DJ. Relationship between simple markers of insulin resistance and coronary artery calcification. J Clin Lipidol. 2017;11(4):1007-1012.

16. Fakhrzadeh H, Sharifi F, Alizadeh M, Arzaghi SM, Tajallizade-Khoob Y, Tootee A, et al. Relationship between insulin resistance and subclinical atherosclerosis in individuals with and without type 2 diabetes mellitus. J Diabetes Metab Disord. 2016 Oct 1;15:41. eCollection 2015.

17. Bonora E, Formentini G, Calcaterra F, Lombardi S, Marini F, Zenari L, et al. HOMA-estimated insulin resistance is an independent predictor of cardiovascular disease in type 2 diabetic subjects: prospective data from the Verona Diabetes Complications Study. Diabetes Care. 2002;25(7):1135-41.

18. Hanley AJ, Williams K, Stern MP, Haffner SM. Homeostasis model assessment of insulin resistance in relation to the incidence of cardiovascular disease: the San Antonio Heart Study. Diabetes Care. 2002;25(7):1177-84.

19. Gast KB, Tjeerdema N, Stijnen T, Smit JW, Dekkers OM. Insulin resistance and risk of incident cardiovascular events in adults without diabetes: meta-analysis. PLoS One. 2012;7(12):e52036. doi: 10.1371/journal.pone.0052036.

20. Mottillo S, Filion KB, Genest J, Joseph L, Pilote L, Poirier $\mathrm{P}$, et al. The metabolic syndrome and cardiovascular risk a systematic review and meta-analysis. J Am Coll Cardiol. 2010 Sep 28;56(14):1113-32. doi: 10.1016/j.jacc.2010.05.034.

21. Sarwar N, Sattar N, Gudnason V, Danesh J. Circulating concentrations of insulin markers and coronary heart disease: a quantitative review of 19 Western prospective studies. Eur Heart J. 2007;28(20):2491-7.

22. Gensini GG. A more meaningful scoring system for determining the severity of coronary artery disease. Am J Cardiol. 1983;51(3):606.

23. Dubinina EE, Burmistrov SO, Khodov DA, Porotov IG. [Oxidative modification of human serum proteins. A method of determining it]. Vopr Med Khim. 1995;41(1):24-6. [Article in Russian].

24. Lelj-Garolla B, Mauk AG. Self-association and chaperone activity of Hsp27 are thermally activated. J Biol Chem. 2006;281(12):8169-74.

25. Ren J, Liu C, Zhao D, Fu J. The role of heat shock protein 70 in oxidant stress and inflammatory injury in quail spleen induced by cold stress. Environ Sci Pollut Res Int. 2018 Jul;25(21):21011-21023. doi: 10.1007/s11356-018-2142-8.

26. Fratelli M, Demol H, Puype M, Casagrande S, Eberini I, Salmona M, et al. Identification by redox proteomics of glutathionylated proteins in oxidatively stressed human $\mathrm{T}$ lymphocytes. Proc Natl Acad Sci U S A. 2002;99(6):3505-10.

27. Bernardo BC, Weeks KL, Patterson NL, McMullen JR. HSP70: therapeutic potential in acute and chronic cardiac disease settings. Future Med Chem. 2016 Dec;8(18):2177-2183.

28. Mandal K, Torsney E, Poloniecki J, Camm AJ, Xu Q, Jahangiri M. Association of high intracellular, but not serum, heat shock protein 70 with postoperative atrial fibrillation. Ann Thorac Surg. 2005 Mar;79(3):865-71; discussion 871.

29. St Rammos K, Koullias GJ, Hassan MO, Argyrakis NP, Voucharas CG, Scarupa SJ, Cowte TG. Low preoperative HSP70 atrial myocardial levels correlate significantly with high incidence of postoperative atrial fibrillation after cardiac surgery. Cardiovasc Surg. 2002 Jun;10(3):228-32.

30. Yuan Y, Pan SS, Shen YJ. Cardioprotection of exercise preconditioning involving heat shock protein 70 and concurrent autophagy: a potential chaperone-assisted selective macroautophagy effect. J Physiol Sci. 2018 Jan;68(1):55-67. doi: 10.1007/s12576-016-0507-7. 